\title{
O HOMEM ABSURDO E O SUICÍDIO SACRIFICIAL EM “O APOCALIPSE DOS TRABALHADORES"
}

\author{
Rogério Caetano de Almeida ${ }^{1}$ \\ Jope Leão Lobo ${ }^{2}$
}

Recebido: 06/04/2015

Aprovado: 14/12/2015

\begin{abstract}
RESUMO: Este artigo pretende analisar como o suicídio possibilita uma profunda tomada de consciência sobre si e o mundo circundante em o apocalipse dos trabalhadores (2013), de Valter Hugo Mãe. Tal perspectiva permitirá analisar o que subjaz ao suicídio dos personagens senhor ferreira e maria da graça e a crítica à exploração, não só do trabalhador, mas do homem em si. A partir da reflexão sobre o mito de Sísifo e sua reverberação no conceito de homem absurdo, de Albert Camus, parte-se para uma interpretação dos detalhes que antecedem os suicídios e suas reverberações na sociedade em que os dois personagens estão inseridos. $\mathrm{O}$ artigo estabelece uma relação entre três temáticas importantes - o trabalho, o absurdo e a morte - através da já referida tomada de consciência, que, inevitavelmente, humaniza e, consequentemente, leva a uma morte sacrificial. Em menor intensidade, outros teóricos foram utilizados quando pertinente. São eles: Karl Marx (1996[1867]) e (1848), Michel Foucault (2010[1972]), Georges Minois (1998[1995]) e Mircea Eliade (1998[1995]).
\end{abstract}

Palavras-chave: Morte sacrificial. O apocalipse dos trabalhadores. Absurdo. Suicídio.

\section{THE ABSURD MAN AND THE SACRIFICIAL DEATH IN APOCALYPSE DOS TRABALHADORES}

\begin{abstract}
This article intends to analyse how the suicide in o apocalipse dos trabalhadores (2013), by Valter Hugo Mãe, is able to make the reader becomes aware of him or herself and of the world. Such perspective will allow the analysis of what underlies the suicide of the characters senhor ferreira and maria da graça and the criticism towards the exploration, not only of the workers, but of man itself. From the reflection on the myth of Sisyphus and its reverberation in the concept of absurd man, Albert Camus, the article proceeds to an interpretation of the details that precede the suicide and its reverberations in society in which the two characters are inserted. This article establishes a relationship between three important themes - work, the absurdity and death - through the aforementioned self-consciousness, which inevitably humanizes and consequently leads to sacrificial death. In a lesser degree, other theorists were used when it was appropriated. They are Karl Marx (1996 [1867]) and (1848), Michel Foucault (2010 [1972]), Georges Minois (1998 [1995]) and Mircea Eliade (1998 [1995]).
\end{abstract}

Keywords: Sacrificial death. O apocalipse dos trabalhadores. Absurd. Suicide.

\footnotetext{
${ }^{1}$ Professor Doutor na Universidade Tecnológica Federal do Paraná (UTFPR).

${ }^{2}$ Bolsista PIBIC em nível de Iniciação Científica na Universidade Tecnológica Federal do Paraná (UTFPR).
} 
É de se notar uma marcante presença de três temas desenvolvidos em $O$ apocalipse dos trabalhadores, de Valter Hugo Mãe: o trabalho, o absurdo e a morte. O primeiro se dá, obviamente, pela relação patrão e empregado. A mesma se desenvolve de forma que a dominação se torne monetária e física para, posteriormente, se tornar psicológica: "e ela respondia, matou-me o senhor ferreira, que há muito me andava a fazer mal e eu até já o via acontecer" (MÃE, 2013, p.10). Percebe-se a preocupação da protagonista maria da graça para com a possibilidade de seu patrão (senhor ferreira) a matar, devido à exploração não só quanto ao trabalho, mas também quanto ao corpo, haja vista ele abusar sexualmente dela. Tais trabalhos se interseccionam com outro grande tema da obra, que envolve a todos os personagens - a mecanização reificadora:

a glória não chegara perto do andriy nem do augusto. a glória não chegara perto da quitéria e não sabia nada sobre a maria da graça. não era dali, como se fosse uma peça de motor e não pertencesse àquela máquina (MÃE, 2013, p.181).

A opção estilística de não escrever nome algum em letras maiúsculas intensifica tal possibilidade de reificação. O trabalho e a reificação contribuem para o desenvolvimento de um outro tema: o suicídio enquanto morte sacrificial em dois personagens - maria da graça e senhor ferreira: "eram menos ainda do que as seis da manhã quando telefonaram à maria da graça com a notícia estranha de que o senhor ferreira se matara. ela ponderou bem o que ouvia e acendeu a luz" (MÃE, 2013, p. 57). Se a morte do patrão que, neste primeiro momento, é dada de maneira abrupta, depois se torna tão lírica quanto a de maria da graça:

viu os estendais, muito lá embaixo carregados de roupas e dispostos como redes sem serventia para a salvarem. via os estendais e hesitava só porque queria ver melhor. naquele tempo, entretida como estava a antecipar uma e outra vez a morte, o senhor ferreira veio das escadas e assomou ao terraço. trazia também um sorriso bonito no rosto e a maria da graça, já nem surpresa, gostou de o ver e recebeu-o. olhou de novo os estendais passivos e foi quando o senhor ferreira a tomou nos braços, avançou um pouco o rebordo do prédio e expôs o corpo dela ao precipício, depois, largou a maria da graça portas da morte adentro. (MÃE, 2013, p.185)

Isto posto, o presente artigo busca conciliar essas três temáticas com a finalidade de analisar como o suicídio sacrificial humaniza e, assim, torna-se um ato lírico. Para isso, desfruta-se dos postulados de diversos autores - Karl Marx, O Capital (1996[1867]) e O manifesto comunista (1848), de José Ortega y Gasset, A desumanização da arte (1991[1925]), Michel Foucault, História da Loucura (2010[1972]), Georges Minois, História do Suicídio 


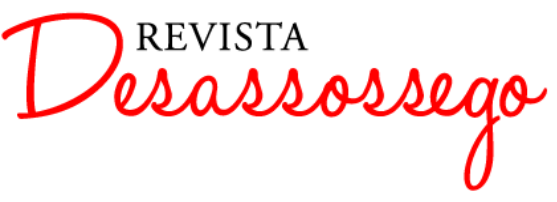

DESASSOSSEGO 14 | DEZ/2015 | ISSN 2175-3180

DOI: http://dx.doi.org/10.11606/issn.2175-3180.v7i14p191-203

(1998[1995]), e de Mircea Eliade, O Sagrado e o Profano (1992) e, fundamentalmente, Albert Camus com seu Mito de Sísifo (2012[1942]),

Como o título indica, a obra o apocalipse dos trabalhadores narra a história, principalmente, de três trabalhadores: maria da graça, quitéria e andriy. Aquela trabalha para um velho depravado, libidinoso e rico chamado senhor ferreira, a segunda trabalha como carpideira, e o último veio da Ucrânia a Portugal em busca de trabalho para conseguir dinheiro e, assim, ajudar os pais (sasha e ekaterina) que estavam sofrendo com dificuldades financeiras devido à crise ucraniana. Dado o título o apocalipse dos trabalhadores, é perceptível que a exploração dos trabalhadores após a crise econômica de 2008-2009 é o tema que se desdobra nas reflexões sobre $O$ homem absurdo e as relações possíveis de se estabelecer com o suicídio sacrificial.

Para Karl Marx houve e sempre haverá luta de classes: "A história de todas as sociedades que existiram até nossos dias tem sido a história das lutas de classes" (MARX; ENGELS, 1848, p.7). Por conseguinte, para o teórico, a história da humanidade se constitui dessa luta entre o opressor e o oprimido. Tal relação se estabelece de maneira patente no enredo construído por Hugo Mãe.

talvez pela injustiça deus devesse aparecer numa altura como essas e não só limpar de novo, e com a mesma impecável qualidade, como dotar as mulheres de uma força incansável, uma energia feliz que não se esgotasse e pudesse contentar os patrões para que lhes pagassem sem hesitação o dobro das misérias que lhes pagavam (MÃE, 2013, p.106).

Conforme podemos observar neste primeiro momento, há uma opressão vinculada à classe social. No entanto, a obra surpreende ao demonstrar que todos somos oprimidos - não é apenas uma opressão que uma classe social impõe à outra, visto que ela existe tanto para com senhor ferreira (homem rico) quanto para com maria da graşa (empregada). A opressão não é apenas da classe trabalhadora como diz Marx, mas do humano - talvez seja mais prudente aqui associar essa exploração com um sentimento íntimo, individual, mais próximo ao Mal-estar na civilizaşão, de S. Freud. Contudo, não podemos considerar apenas a perspectiva do indivíduo. Assim, Marx mostra uma perspectiva do funcionamento econômico da sociedade capitalista:

Genericamente, quanto maior a força produtiva do trabalho tanto menor o tempo de trabalho exigido para a produção de um artigo, tanto menor a massa de trabalho nele cristalizada, tanto menor o seu valor. Inversamente, quanto menor a força produtiva do trabalho, tanto maior o tempo de trabalho necessário para a produção de um artigo, tanto 


\section{Dibianung}

DESASSOSSEGO 14 | DEZ/2015 | ISSN 2175-3180

DOI: http://dx.doi.org/10.11606/issn.2175-3180.v7i14p191-203

maior o seu valor. A grandeza do valor de uma mercadoria muda na razão direta do quantum, e na razão inversa da força produtiva do trabalho que nela se realiza (MARX, 1996, p.170).

De acordo com Marx, quanto maior o tempo exigido para a produção de um produto, maior o seu valor, assim também quanto maior a força produtiva, ou seja, a eficácia da produtividade, menor o tempo necessário para a produção e, portanto, menor o valor. Para explicar, Marx usa o exemplo dos artesãos e da indústria. A indústria consegue reduzir o preço do produto do artesão diminuindo o tempo de produção de um produto, como o sapato, por exemplo. $\mathrm{O}$ artesão não consegue encurtar esse tempo, portanto, é impossível competir com o valor dos produtos industrializados, visto que não é capaz de reduzir o preço de seu produto. Comparando tal ideia ao mito de Sísifo, há um ponto de encontro com o livro que nos fará compreender a razão do ambiente insalubre do mesmo. Sísifo, por rebeldia aos deuses, foi condenado a levar uma pedra ao topo de uma montanha durante toda a eternidade, pois quando a pedra chegava ao topo uma força irreversível a derrubava.

Relacionando tal mito ao conceito de Marx, pode-se imaginar que a pedra seja o preço do trabalho; a montanha, a força de produção; e a força irreversível, o tempo. O homem quer chegar até o cume da força de produção para, assim, deixar o preço do trabalho alto. Isso representa, então, o trabalhador empurrando a pedra até o topo da montanha. Porém, como o aumento da força de produção diminui o tempo de trabalho (a força irreversível), por conseguinte, o preço do trabalho também reduz, já que o homem é pago pelo tempo de serviço e não quantidade. Portanto, a maximização da força de produção torna-se irrisória, inclusive se o esforço for acumulativo e a pedra que cai da montanha projeta o homem conjuntamente.

Há, portanto, um ciclo em que toda vez que um homem tentar aumentar sua força de produção o preço de seu trabalho reduz; com isso, ele terá que aumentar a força de produção novamente o que fará o preço cair novamente. Essa ideia contida na relação do mito de Sísifo com a maneira como Marx acredita funcionar o capitalismo será chamada, aqui, de espiral de Sísifo, posto que se repete infinitamente. Prevê-se disso que em algum momento a força de produtividade terá de ser tão grande que será humanamente impossível aumentá-la. $\mathrm{Na}$ obra, tal situação absurda, mas não tão inusitada assim na exploração/opressão do trabalhador, faz com que dois "serviços" sejam prestados para que 
o patrão lhe pague o preço de um: essa multiplicação se sucede com a empregada maria da graça que faz a limpeza da casa do senhor ferreira e empresta seu corpo, sem consentimento, para o trabalho sexual. Posteriormente, vemos que a espiral de Sísifo se perpetua no livro. Após a morte de seu patrão, maria da graça, seja maquinalmente ou para sobreviver, oferece os mesmos tipos de serviços para quem a contratar:

o mikhalkov surpreendeu-se, sorriu e reparou no agitado das mãos da mulher. um rubor na pele exalava o ar, poros todos, como a sofrer. o mikhalkov pousou o que trazia na mão, entrou na casa de banho e tomou-a sem licenças. ela disse-lhe, por favor, por favor. e ele não teve dúvidas de que lhe implorava que a tivesse. (MÃE, 2013, p.111-112)

Conforme indicado acima, pode-se verificar neste trecho que ela também presta dois serviços: é empregada do mikhalkov e presta outro serviço - "maria da graça sentiu que cobrava oito euros por ser puta." (MÃE, 2013 p.121). Assim, a personagem tem dúvidas quanto a qual serviço presta (prostituta ou empregada?). Não surpreendente numa atmosfera machista é que a mesma coisa ocorra na relação com o marido (angusto). Este quer, devido ao "contrato" do casamento, que ela seja mulher, no estrito sentido sexual, cozinheira, empregada doméstica e que execute tarefas de manutenção na casa, como pintura para esconder as rachaduras. Observa-se, portanto, na obra a espiral de Sísifo nas relações opressoras entre patrão e empregado; marido e esposa; e, homem e mulher.

Há uma relação íntima entre o trabalho do oprimido e o tempo, afinal este mensura a valorização e/ou a desvalorização da força de trabalho (a pedra, na comparação que estabelecemos com o mito de Sísifo). Não há como suspender a passagem do tempo (força irreversível). Para estagná-lo, ou deixar de ter consciência dele, deve-se abster da condição de humano, tornando-se, portanto, coisa. Dada nossa consciência do tempo, somos afetados por sua duração, diferentemente das máquinas e objetos. Por outro lado, os humanos não podem trabalhar - fazer aquilo que lhes é exigido - o tempo inteiro. Não se pode ser o próprio trabalho, ainda que se deseje, visto que muitos se classificam de acordo com suas funções sociais. Tal perspectiva se encontra no livro pela comparação das personagens com máquinas:

a glória não chegara perto do andriy nem do augusto. a glória não chegara perto da quitéria e não sabia nada sobre a maria da graça. não era dali, como se fosse uma peça de motor e não pertencesse àquela máquina. (MÃE, 2013, p.181)

o andriy procurou a quitéria sem grandes rodeios. não era uma inversão 
na sua mutação para máquina, era apenas uma peça se encaixando-se. seria mais equilibrada a vida se cada assunto ficasse pacificado. (MÃE, 2013, p.64)

e os pais estranhamente, emudeceram para sempre, ficando o filho sozinho no país das flores, forçando o coração a ganhar foles, deitar fumo, substituir o sangue por óleo, verter para os outros órgãos como dentro de um motor, tendo radiador, ventoinhas, estruturas inoxidáveis no caminho do esqueleto, propulsores, tubos comunicantes, roldanas, anilhas e parafusos, mecanismos dentados como a ferrarem-se impiedosamente uns nos outros e para sempre, visores perfeitos para o futuro coberto de ouro, já muito mais fácil de existir. (MÃE, 2013, p.8384)

Esses trechos evidenciam a mecanização do humano. Percebe-se que no primeiro fragmento o narrador compara gloria, entre outros, a uma peça de motor. Dado o fato de que todos pertencem a uma máquina específica, gloria deveria pertencer a um outro motor, a uma outra máquina - ela não pertence àquele espaço. No segundo, andriy sofre mutação gradualmente para máquina. Tal perspectiva fica evidente quando o discurso indireto livre aponta: "seria mais equilibrada a vida se cada assunto ficasse pacificado" (MÃE, 2013, p.64). Além disso, esse personagem buscava o que imaginava ser a felicidade das máquinas. Tal felicidade seria alcançar cada meta, "sempre tão definida e cumprida quanto seria de esperar" (MÃE, 2013, p.51).

Para corroborar a ideia de que essa personagem desejava ser máquina, andriy gostava de acreditar que a vida podia existir como uma máquina de trabalho perfeita, pois assim ele conseguiria mandar dinheiro a sua família ucraniana. Tal possibilidade se ratifica com o fato que andriy preocupa-se, quando começou a deitar-se com quitéria, afinal ele não queria "que isso o demovesse da progressiva metalização do corpo" (MÃE, 2013, p.72) e "tinha medo, porque por ela perderia a possibilidade de ser feliz e voltaria a condição humana" (MÃE, 2013, p.98). O motivo dessa vontade de ser máquina era exatamente a tentativa de anular o tempo (a força irreversível) da espiral de Sísifo para que fosse a máquina de trabalho perfeita e, assim, ganhar dinheiro suficiente para mandar aos pais. No terceiro excerto, o narrador não só compara todo o corpo de andriy a uma máquina, mas corrobora com a interpretação feita de que a personagem quer se submeter a uma condição de máquina para conseguir "o futuro coberto de ouro, já muito mais fácil de existir".

Dessa forma, observa-se a desumanização do humano, já que o personagem andriy quer se afastar de sua condição humana para poder enriquecer e enviar dinheiro aos pais. 


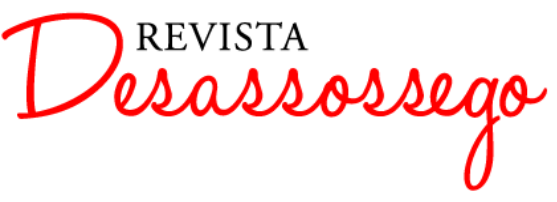

DESASSOSSEGO 14 | DEZ/2015 | ISSN 2175-3180

DOI: http://dx.doi.org/10.11606/issn.2175-3180.v7i14p191-203

andriy ativamente se desumaniza para ganhar dinheiro virando máquina. Encontramos um paralelo em Ortega y Gasset, em suas reflexões sobre a desumanização da arte: “[...] a arte de que falamos não é só inumana por não conter coisas humanas, senão que consiste ativamente nessa operação de desumanizar" (ORTEGA Y GASSET, 1991, p.42). Contudo, em o apocalipse dos trabalhadores o autor não altera a realidade como o pintor, mas mostra o quanto ela é absurda. Aí temos, portanto, o mundo absurdo.

Segundo Camus, essa insalubridade gerada pela mecanização (desumanização) é o absurdo: "Esse mal-estar diante da desumanidade do próprio homem, essa incalculável queda diante da imagem daquilo que somos, essa 'náusea', como diz um autor dos nossos dias, é também o absurdo" (CAMUS, 2012, p.29). Além disso, é esse mundo absurdo que gera a opressão tanto da classe trabalhadora quanto da abastada, afinal um se desumaniza pela necessidade de ser máquina e o outro por tomar atitudes tão contrárias à humanidade, como, por exemplo, abusar do corpo da empregada, que aprisiona o homem a ponto de ele desejar ser coisa e tornar-se, conscientemente, como andriy opta por fazer.

A ideia contraditória de ser humano e não o ser ao mesmo tempo, por meio do mito de Sísifo, não é nova. A. Camus já demonstrou essa semelhança ao falar que "o operário de hoje trabalha todos os dias de sua vida nas mesmas tarefas, e esse destino não é menos absurdo" (CAMUS, 2012, p.123) que o de Sísifo. A espiral de Sísifo explica apenas a opressão cada vez maior da classe trabalhadora, comprimindo-a irrevogavelmente ao trabalho. Todavia, vimos que o senhor ferreira, o patrão que não precisa trabalhar para viver, também é oprimido. Neste sentido, podemos demonstrar como isso se sucede com o patrão por meio do absurdo.

Primeiramente, temos o discurso do inválido como alguém sem valor, mesmo que este tenha a atitude humana de ler "os versos de rainer maria rilke para fecundar no filho o sentir e ver das coisas invisíveis e indizíveis" (MÃE, 2013, p.63), como o pai do patrão de maria da graça. É contraditório considerar alguém sem valor ou inválido por simplesmente não poder trabalhar e, como extensão dessa lógica, não ser feliz por não acumular capital. Logo, a ideologia propagada por esse sistema beira uma desumanização absurda que, de certa forma, se vincula às reflexões sobre o homem absurdo. Justamente por esse conceito de felicidade associado ao dinheiro e o de invalidez associado àquele que não pode trabalhar, que o senhor ferreira é “(...)incapaz de perdoar ao mundo a morte do pai e a ideia tão capitalista de felicidade” (MÃE, 2013, p.145). 


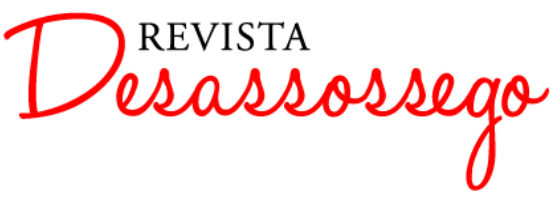

DESASSOSSEGO 14 | DEZ/2015 | ISSN 2175-3180

DOI: http://dx.doi.org/10.11606/issn.2175-3180.v7i14p191-203

Temos aqui, portanto, um homem absurdo, pois ele perde sua esperança quando seu pai morre sem ser desesperado. Ele se recusa a continuar crendo em ideologias e carrega consigo uma insatisfação consciente, portanto se rebela contra o mundo em que vive, mas, ao mesmo tempo, torna-se opressor na espiral de Sísifo na relação que estabelece com maria da graça. Logo, os requisitos de contraditoriedade, de "ausência de esperança (que nada tem a ver com o desespero)" (CAMUS, 2012, p.42), de "recusa contínua (que não deve ser confundida com a renúncia)" (idem) e de "insatisfação consciente (que não se poderia assimilar à inquietude juvenil)" (idem), próprios do absurdo, são facilmente encontrados no senhor ferreira.

A personificação do cão portugal é outro elemento do absurdo. Não pela personificação em si, mas pelo fato de o cão ter uma visão mais humana do que o próprio ser humano: "o portugal as vezes pressentia aqueles pensamentos e latia, ela dizia, cala-te, palerma, onde é que já se viu um país ladrar" (MÃE, 2013, p.141). O país ladra porque assim como o cão se humaniza, o homem, na figura abstrata do Estado, desumaniza a outros homens e a si mesmo. Assim sendo, "o absurdo nasce desse confronto entre o apelo humano e o silêncio irracional do mundo" (CAMUS, 2012, p.39). Ao refletirmos sobre uma macroestrutura social, o mundo absurdo desse país nasce, então, do confronto entre o apelo dos humanos que não sentem mais ("cala-te, palerma") e o silêncio de um país tão irracional quanto um cachorro, afinal, ambos não fazem nada contra a irracionalidade do sistema em que maria da graça está inserida.

Podemos notar, ainda, a espiral de Sísifo e, consequentemente, o absurdo na estrutura d'o apocalipse dos trabalhadores. É recorrente no livro uma pequena cena ser interrompida no clímax, ser praticamente esquecida, pois outro pequeno quadro narrativo é dado, e, neste momento, retomada e ressignificada. Como exemplo, podemos pegar a primeira cena, da página 115 do livro (a obra não dispõe de capítulos), que é um sonho de maria da graça pedindo a São Pedro para entrar no céu e ver o senhor ferreira. Nessa parte, temos o clímax na fala do santo: "vai te embora mulher não entendes que não vale a pena morrer de amor" (MÃE, 2013, p.116). A retomada ocorre quase no encerramento do capítulo: "acha que isso é morrer de amor, gritou, acha mesmo" (MÃE, 2013, p.121), quando maria das graças reflete sobre as semelhanças e diferenças entre o amor e a violação.

A construção se faz numa complementaridade em que a cena anterior é retomada pela posterior e só faz sentido quando o quadro inteiro é exposto. E a cena posterior se 


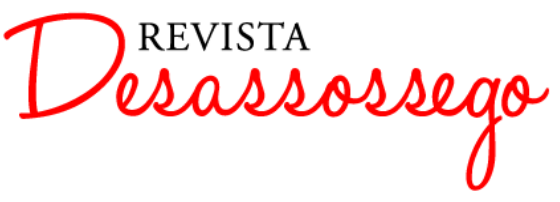

DESASSOSSEGO 14 | DEZ/2015 | ISSN 2175-3180

DOI: http://dx.doi.org/10.11606/issn.2175-3180.v7i14p191-203

constrói, ganha significado, e progride a partir do que foi apresentado anteriormente. A espiral completa sua volta sem ter um fim - Sísifo sobe novamente à montanha com uma pedra nas costas sem atingir o cume, ou, supostamente atingindo-o, vê-se que o rolar da pedra para baixo é o que nos delicia, dando um todo orgânico à obra. Assim, o apocalipse dos trabalhadores é uma matéria viva que sofre, e nos faz sofrer, quando vemos a absurdidade que é o trabalho e a existência de Sísifo, o homem comum. Desse modo, a existência em $o$ apocalipse dos trabalhadores é absurda, sem um sentido aparente, seja na opressão do trabalhador, nas relações amorosas e até nas políticas do estado. Uma possibilidade de fuga de tal lógica estaria no suicídio consciente que os protagonistas adotam, o que fere os pressupostos de Camus sobre o absurdo.

Assim, a morte ou suicídio do senhor ferreira, a princípio, faz com que ele não seja um homem absurdo. No entanto, ele estava apaixonado pela vida: "a agente quental interrompia a maria da graça e perguntava, o que quer dizer com isso. para provar que morria apaixonado pela vida, como se morresse em protesto, explicava a maria da graça à outra que não entendia nada e queria saber sempre melhor” (MÃE, 2013, p. 58). Assim, por que se matar? Camus possui uma explicação convincente a respeito: "Kirilov deve então se matar por amor à humanidade. Deve mostrar a seus irmãos uma via real e difícil que será o primeiro a percorrer. É um suicídio pedagógico, e por isso Kirilov se sacrifica" (CAMUS, 2012, p.109). Há, então, as duas possibilidades para o suicídio: por amor e por pedagogia e elas, juntas, tornam-se sacrificiais.

Se tal suicídio foi por amor, só pode ser por amor à maria da graça, visto que deixou a casa e o dinheiro que possuía para ela. Outra perspectiva é a oferecida na seguinte passagem: "julgou que ela se desculpava de nada, de susto ou compaixão, talvez pena dele, como haveria ele de se expor ali muito fraco, vulnerável demais, diante de uma maria da graça que, obviamente, só poderia amar (MÃE, 2013, p. 144-145)”. Uma leitura possível é de que senhor ferreira possuía maria da graşa, o que impossibilitava o amor entre ambos. Ambos se desumanizaram na relação maquinal e absurdamente construída. Obviamente, as questões da posse e da relação maquinal tem a ver com a existência, portanto não se prende às relações sexuais de ambos. maria da graça era obrigada, por exemplo, a contemplar quadros de Goya.

Sem entendê-los, sem poder sair de sua situação social de empregada, sem poder se casar com o senhor ferreira, ela não poderia ser humanizada e a vida dada não permitiria tal 


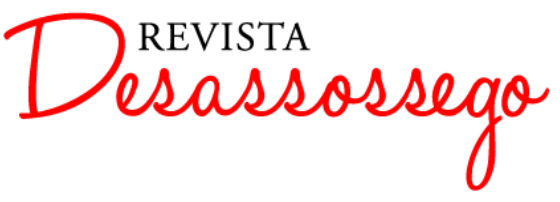

DESASSOSSEGO 14 | DEZ/2015 | ISSN 2175-3180

DOI: http://dx.doi.org/10.11606/issn.2175-3180.v7i14p191-203

humanização à maria da graça. A espiral de Sísifo se consuma sobre a vida da protagonista. Desta forma, o senhor ferreira é um homem absurdo revoltado - revoltado a partir da profunda consciência que tem do mundo como absurdo. Ele é incapaz de perdoar o mundo devido à morte de seu pai, é incapaz de compreender a felicidade associada ao dinheiro, é incapaz de propor casamento à serviçal mulher casada que ama e estupra. Para ele, a felicidade é estar com a pessoa amada:

a felicidade, disse-lhe, é posta diante de nós como extremidade do dinheiro. levantou-se, abriu a janela e ela levantou-se também seguindo de pés descalços para seu lado. haveríamos de ser felizes de verdade, coisa que só é possível se tivermos quem amamos por perto (MÃE, 2013, p.145).

Já que ele não poderia estar com as pessoas que amava - o pai por estar morto e maria da graça por ter sido submetida a uma desumanização na espiral de Sísifo por contribuição dele -, resta, como no exemplo de Kirilov, dado por Camus, mostrar uma via real e difícil de percorrer por meio do suicídio pedagógico e do sacrifício. Assim, a morte voluntária do senhor ferreira "é uma censura e uma acusação, talvez mesmo um insulto aos vivos e, sobretudo, àqueles que zelam pelo bem-estar da humanidade" (MINOIS, 1998, p.144).

Tal morte é uma censura ao mundo absurdo, com o qual ele é revoltado, e uma acusação à espiral de Sísifo e a si mesmo por fazer parte dessa desumanização causada pelo sistema. Isso pode ser evidenciado pela passagem: "um protesto, como uma morte sindical, a reclamar por todos quanto tinham de morrer por razões indignas da elevação humana" (MÃE, 2013, p. 59). Justamente por isso, essa morte voluntária é uma "recusa do triunfo da opressão” (MINOIS, 1998, p. 380). O outro fato, e o mais importante, é que ele quer ensinar às pessoas, e principalmente, à maria da graça como se libertar desse mundo absurdo, dessa espiral de Sísifo.

O suicídio, planejado nos mínimos detalhes - ele deixa uma quantidade elevada de dinheiro para que a polícia encontre -, foi extremamente chamativo (música de Mozart alta, por exemplo) e, como Minois (1998) afirma, um insulto aos vivos. Por isso mesmo a polícia deveria agir rápido já que "logo estariam as crianças passando para as escolas e era mesmo a tempo de se pôr tudo como se nada tivesse sido, para não assustar os pequenos e pacificar o povo de bragança” (MÃE, 2013, p. 71). Além disso, outra pessoa pegando tal quantia iria mostrar à empregada que o próprio sistema não a deixaria ter dinheiro (ela 
sempre soube do local em que o dinheiro ficava). É exatamente isso que ocorre, a agente quental acha o dinheiro e, em nenhum momento, o devolve à herdeira.

O suicídio não é em vão. maria da graça percebe que não poderia escapar dessa lógica de desumanização e reificação de outra forma que não fosse se suicidando também e, portanto, libertando-se. Logo, o senhor ferreira ensina e resiste ao mundo absurdo quando se sacrifica para demonstrar como se livrar dessa opressão causada pelo mundo absurdo. Com sua consciência do absurdo, ele retorna à condição humana se sacrificando. Além disso, a morte do senhor ferreira é absurda, pois, ela, assim como a obra absurda "marca ao mesmo tempo a morte de uma experiência e sua multiplicação" (CAMUS, 2012, p. 98). Marca, portanto, o fim da experiência de ferreira e se replica na morte, enquanto tomada de consciência e (re)humanização, de maria da graça.

viu os estendais, muito lá embaixo carregados de roupas e dispostos como redes sem serventia para a salvarem. via os estendais e hesitava só porque queria ver melhor. naquele tempo, entretida como estava a antecipar uma e outra vez a morte, o senhor ferreira veio das escadas e assomou ao terraço. trazia também um sorriso bonito no rosto e a maria da graça, já nem surpresa, gostou de o ver e recebeu-o. olhou de novo os estendais passivos e foi quando o senhor ferreira a tomou nos braços, avançou um pouco o rebordo do prédio e expôs o corpo dela ao precipício, depois, largou a maria da graça portas da morte adentro (MÃE, 2013, p. 185).

Assim, após o reencontro com ferreira, o voo de passagem para a liberdade. Conforme vemos em Mircea Eliade (1992, p. 85), o suicídio pode ser uma representação de liberdade: "Mas os dois significados do 'vôo' dos Arhats exprimem a rotura de nível ontológico e a passagem de um modo de ser a outro, ou, mais exatamente, a passagem da existência condicionada a um modo de ser não condicionado, quer dizer, de perfeita liberdade." Ambos os suicídios são libertadores. Conforme dito anteriormente, estar preso à espiral de Sísifo, seja no que tange à relação com o trabalho ou no que tange à relação com a própria existência, gera a desumanização e/ou a reificação do homem. Portanto, enquanto maria da graça estivesse presa ao senhor ferreira e a trabalhos similares que exercia, ela estaria fadada à reificação; e, enquanto o senhor ferreira estivesse reificando maria da graça, ele também se desumanizaria. Então, os dois suicídios humanizaram as personagens e dá a eles a consciência do mundo absurdo.

Segundo elucidação de Georges Minois, os tipos de suicídio que mais facilmente se aproximam do levado a cabo por maria das graças são os associados ao amor e à loucura. 


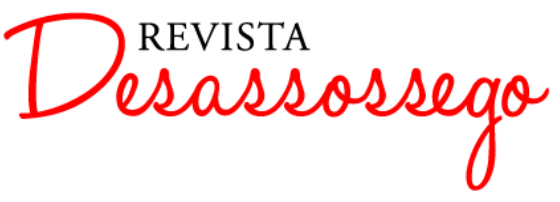

DESASSOSSEGO 14 | DEZ/2015 | ISSN 2175-3180

DOI: http://dx.doi.org/10.11606/issn.2175-3180.v7i14p191-203

A protagonista chega a afirmar à sua amiga e confidente, quitéria, que amava o senhor ferreira. Ao longo da narrativa, sonha inúmeras vezes ir ao céu porque queria ver seu patrão, mas São Pedro não a deixava entrar nas portas do céu. Em outra perspectiva, há uma consciência mínima de sua humanidade, possível apenas por conta das intervenções dele: “o senhor ferreira, lembrava-se, aquele traste velho que usando-a também a levava para o mais perto de se ser humano, importando-se com a instrução da sua alma para as coisas imateriais, as verdadeiramente enriquecedoras" (MÃE, 2013, p. 180).

Porém, não pode ser só isso, afinal em um dos sonhos dessa personagem São Pedro discute sobre a vontade que maria da graça possuía de morrer por amor: "respondeulhe, não te deixarei morrer assim, mesmo estúpida e tão malcriada, se quiseres passar por esta porta vais ter de conseguir melhor pretexto" (MÃE, 2013, p.117). Dito isso, percebe-se que o desejo expresso é de morrer por algo maior que o amor. Qual seria, portanto, esse pretexto digno de uma morte voluntária? Não seria a libertação da absurda espiral de Sísifo e, consequente, humanização? Afinal, a "Loucura é esta renúncia ao mundo; loucura, o abandono à vontade obscura de Deus; loucura, esta procura cujo fim não se conhece esses são outros tantos temas caros aos místicos" (FOUCAULT, 2010, p.32). Então, a loucura seria uma espécie de entendimento da absurdidade do mundo, uma tomada de consciência que a faz renunciar ao mundo. Assim sendo, tal qual o senhor ferreira, ela protestou.

Podemos dizer ainda, que o senhor ferreira poderia ter se casado com maria da graça e isso teria o mesmo resultado dos suicídios. Entretanto, há um regime de castas sociais que não veria com bons olhos a união de classes com status social tão diferente, pensariam que ela não teria se casado com ele por amor, mas por dinheiro. Isso fica indicado pela desconfiança que a agente quental tem por maria da graşa: "a agente quental encarou-a implacável, como capaz até de a prender, e confessou-lhe o que ia na cabeça, você é uma mulher bizarra, dona maria da graça pragal, é uma mulher perigosa, diga-me que não é" (MÃE, 2013, p. 75). Além disso, ambos não se humanizariam, ou se humanizariam apenas parcialmente. O suicídio proporciona uma ascensão a um estado humano, ou seja, sacrificou a própria vida para morrer de forma digna, como humano e não como coisa ou objeto sexual para seus futuros patrões.

Por último, antes de se jogar do prédio, ela vê pássaros (outro símbolo de liberdade): "alguns pássaros ocorreram àquele lugar, punham-se de um lado para o outro, 
pousando em cima dos trastes velhos ali encostados e chilreavam, às vezes muito intensamente. que tontos pareciam à maria da graça, tão estranhamente alegres" (MÃE, 2013, p.184). Há, portanto, no suicídio das personagens, uma morte sacrificial e um forte apelo à liberdade. Logo, o que subjaz a tal ato é um voo à morte como o único meio de humanização, pois ambos estavam presos a um sistema cujo funcionamento causa a desumanização, o apocalipse do trabalhador. O suicídio, sacrificial, é não só uma tomada de consciência, um entendimento do mundo absurdo, mas uma metáfora da liberdade que nos é retirada, e aqui mimetizamos, aos poucos, em nossa experiência cotidiana.

O leitor de o apocalipse dos trabalhadores também morre com a obra e renasce menos mecânico, menos reificado. $O$ homem absurdo que torna, compreendendo toda a absurdidade, é, ao menos, mais humano.

\section{REFERÊNCIAS}

CAMUS, Albert. O Mito de Sísifo. Rio de Janeiro: BestBolso, 2012.

ELIADE, Mircea. O Sagrado e O Profano. São Paulo: Martins Fontes, 1992.

FREUD, Sigmund. Interpretação dos Sonhos. Rio de Janeiro: Imago, 2001.

FOUCAULT, Michel. História da Loucura. São Paulo: Perspectiva, 2010.

MÃE, Valter Hugo. o apocalipse dos trabalhadores. São Paulo: Cosac Naify, 2013.

MARX, Karl; ENGELS, Friedrich. Manifesto comunista. Disponível em: http://pensamentosnomadas.files.wordpress.com/2012/03/lido-manifesto-comunista.pdf. Acessado em: 15 Fev 2014.

MARX, Karl, O Capital. São Paulo: Editora Nova Cultural Ltda, 1996.

MINOIS, George. História do Suicídio. Lisboa: Teorema, 1998.

ORTEGA Y GASSET, José. A desumanização da arte, São Paulo: Cortez, 1991. 